\title{
Prevalence of "unclassified" HPV genotypes among women with abnormal cytology
}

\author{
Clorinda Annunziata', Giovanni Stellato ${ }^{2}$, Stefano Greggi ${ }^{2}$, Veronica Sanna ${ }^{3}$, Maria Pia Curcio ${ }^{3}$, Simona Losito ${ }^{3}$, \\ Gerardo Botti ${ }^{3}$, Luigi Buonaguro', Franco Maria Buonaguro ${ }^{1}$ and Maria Lina Tornesello ${ }^{1 *}$ (D
}

\begin{abstract}
Background: High risk human papillomaviruses (HPVs) have been unequivocally recognised as the necessary cause of squamous intraepithelial lesions (SIL) and invasive carcinoma of the cervix. The distribution and the role of unclassified risk HPV genotypes in cervical neoplasia has not been fully elucidated.

Methods: Liquid-based cytological samples were collected from 337 women referred for colposcopy following an abnormal cytological diagnosis. HPV DNA was detected by broad-spectrum PCR and genotypes identified by nucleotide sequencing analysis and reverse line blot (RLB).

Results: The overall frequency of HPV infection was 36.5\% (35 out of 96) in samples negative for intraepithelial lesions or malignancy (NILM), 80\% (181 out of 226) in low grade SIL and 93.3\% (14 out of 15) in high grade SIL ( $P<$ 0.001). Thirty-five different genotypes were identified among the $230 \mathrm{HPV}$-positive cases. The Group 1 oncogenic viruses (HPV16, 18, 31, 33, 35, 39, 45, 51, 52, 56, 58 and 59) were found in 21.9, 46.5, and 86.7\% of NILM, low grade SIL and high grade SIL, respectively. The Group 2A, including the probably oncogenic virus HPV68, was found in 1 and $0.8 \%$ of NILM and low grade SIL, respectively. The Group 2b possibly oncogenic HPVs (HPV34, 53, 66, 67, 70, 73, 82 and 85 ) were found in $4.2,21.7$ and $26.7 \%$ of NILM, low grade SIL and high grade SIL, respectively. The unclassified viruses (HPV12, 42, 54, 55, 61, 62, 81, 83, 84, 89, 90, 91) were detected in 8.3 and 14.6\% of NILM and low grade SIL, respectively, and never in high grade SIL.

Conclusions: Group 1 HPVs were mainly prevalent in high grade SIL and low grade SIL while Group 2B were equally distributed among the two groups. The dominant frequency of unclassified HPVs in low grade SIL and NILM and their rarity in high grade SIL suggests their marginal role in cervical neoplasia of the studied population.
\end{abstract}

Keywords: Human papillomavirus, Cervix carcinoma, Squamous intraepithelial neoplasia

\section{Background}

Human papillomaviruses (HPVs) of the genus alpha represent the most common sexually transmitted viruses infecting mucosal epithelial cells of male and female genital tract [1-3]. Alpha HPVs currently comprise 62 genotypes classified in 15 species on the basis of their phylogenetic similarity [4-6]. The oncogenic risk of mucosal HPVs has been established by large epidemiological studies investigating the different prevalence of specific genotypes in normal cytology, in low and high grade cervical intraepithelial lesions (SIL) and in cervical

\footnotetext{
* Correspondence: m.tornesello@istitutotumori.na.it

${ }^{1}$ Molecular Biology and Viral Oncology Unit, Istituto Nazionale Tumori IRCCS

"Fondazione G. Pascale", via M Semmola, 80131 Naples, Italy

Full list of author information is available at the end of the article
}

carcinoma [7-9]. Twelve viruses (HPV16, 18, 31, 33, 35, $39,45,51,52,56,58$ and 59) have been found significantly associated with cervical carcinoma and classified as Group 1 "carcinogenic to humans", one virus (HPV68) as Group 2A "probably carcinogenic to humans", 12 viruses (HPV26, 53, 66, 67, 70, 73, 82, 30, $34,69,85,97$ ) as Group 2B "possibly carcinogenic to humans" and two viruses (HPV6 and 11) as Group 3 "unclassifiable as to carcinogenicity in humans" [10]. Several other HPV genotypes are unclassified regarding to their epidemiologic oncogenic risk although few of them have been shown to bind and to ubiquitinate p53 oncosuppressor with the same efficiency as the Group 1 oncogenic viruses $[11,12]$.

(C) The Author(s). 2018 Open Access This article is distributed under the terms of the Creative Commons Attribution 4.0 International License (http://creativecommons.org/licenses/by/4.0/), which permits unrestricted use, distribution, and reproduction in any medium, provided you give appropriate credit to the original author(s) and the source, provide a link to the Creative Commons license, and indicate if changes were made. The Creative Commons Public Domain Dedication waiver (http://creativecommons.org/publicdomain/zero/1.0/) applies to the data made available in this article, unless otherwise stated. 
A meta-analysis of HPV genotype distribution among 115,789 women positive for HPV infection, including normal cytology, atypical squamous cells of undetermined significance (ASCUS), low grade SIL, high grade SIL and invasive cervical cancer cases, showed limited difference in the prevalence of Group 1 HPV type distribution among all groups while HPV16, HPV18 and 45 were relatively high frequent in cervical carcinoma [7]. Moreover, a large meta analysis, comprising above one million women with normal cervical cytology, showed that Group $1 \mathrm{HPV}$ genotypes were found to be the most common viruses in the general female population worldwide, accounting for $70 \%$ of HPV infections in normal cytological samples [13]. Some HPV genotypes belonging to the Groups 2A and 2B, namely HPV26, 67, 68, 69, 73 and 82 , were found also relatively common in invasive cervical cancer compared to normal cytology [2]. Conversely, Group 2A/2B HPV53 and 66 were found more common in normal cytology and low grade SIL than in invasive cervical cancer. Among viruses with unclassified risk the HPV61, 62, 84 and 89 have been found to be relatively uncommon in normal cytology and invasive cancer and more frequent in low grade SIL [2].

In Italy, several studies evaluating the HPV prevalence and genotype distribution have been performed among women enrolled in organized and in opportunistic screening programs [14-17]. All the studies confirmed the high prevalence of Group $1 \mathrm{HPV}$ genotypes, particularly HP16, 31 and 18 in SIL and invasive cervical cancer [17-19]. However, some unclassified HPVs have been also found to be relatively common in women with normal cytology. In particular, Tornesello et al. observed that several unknown risk viruses were present in low-grade SIL (HPV30, 32), in high-grade SIL (HPV62, 90), and in a small percentage of cervical carcinoma (HPV62) [16, 20]. More recently, Del Prete et al. reported that among 2149 women enrolled in Apulia region the HPV42 was the most common genotype followed by HPV16 with frequency rates of 10.7 and $8.9 \%$, respectively [21].

In the present study we aimed to expand previous analyses on the distribution of alpha HPV genotypes among Italian women referred to the colposcopy outpatient clinic of the Istituto Nazionale Tumori of Napoli after an abnormal cytological diagnosis. We used broad spectrum amplification technology followed by nucleotide sequencing analysis in order to identify known and unknown HPV genotypes infecting the analyzed women population. All HPVs not included in the Group 1, 2A, 2B and 3 have been designed as unclassified HPVs in the present study.

\section{Methods}

\section{Patients and samples}

Cervical cytological samples were collected in liquid-based PreservCyt (Hologic Inc., Marlborough, MA) from 337
Italian women which following a primary abnormal cytological test were referred for a colposcopy examination and directed biopsy at the Istituto Nazionale Tumori "Fond Pascale" from January 2015 to December 2017. All women enrolled in the study self-reported to be not HIV positive or pregnant. Cytology results were recorded according to the Bethesda system as negative for intraepithelial lesions and malignancy (NILM), low grade squamous intraepithelial lesion (SIL) and high grade SIL. Histological diagnoses were available for 224 women and cervical lesions were classified as cervical intraepithelial neoplasia of grade 1, 2 and 3 (CIN1, 2 and 3).

This study was approved by the Institutional Scientific Board of the Istituto Nazionale Tumori "Fond Pascale", and it is in accordance with the principles of the Declaration of Helsinki. All patients provided written informed consent.

\section{DNA isolation}

PreservCyt specimens were vortexed briefly, divided into two 2-ml aliquots and centrifuged $5 \mathrm{~min}$ at $12^{\prime} 000 \mathrm{~g}$. The cell pellet was washed twice with phosphate buffered saline (PBS Buffer, $137 \mathrm{mM} \mathrm{NaCl}, 2.7 \mathrm{mM} \mathrm{KCl}$, $8 \mathrm{mM}$ Na2HPO4, and $2 \mathrm{mM}$ KH2PO4, pH 7.4) and resuspended in $100 \mu \mathrm{l}$ of lysis buffer $(50 \mathrm{mM}$ Tris- $\mathrm{HCl}$ $\mathrm{pH}$ 8.5, $1 \mathrm{mM}$ EDTA, 0.5\% Tween20) containing proteinase $\mathrm{K}(200 \mu \mathrm{g}$ per $\mathrm{ml})$. Cell lysates were digested at $60{ }^{\circ} \mathrm{C}$ for $30 \mathrm{~min}$. DNA was purified by phenol and phenol-chloroform-isoamyl alcohol (25:24:1) extraction and concentrated by ethanol precipitation in $0.3 \mathrm{M}$ sodium acetate $(\mathrm{pH} 4.6)$. The quantity of isolated DNA was assessed using the spectrophotometer Nanodrop 2000C (Thermo Fisher Scientific, Waltham, MA).

\section{Broad spectrum HPV amplification and genotyping}

Nucleic acid integrity was assessed by PCR amplification of TP53 gene exon 7 which rendered all 337 samples suitable for further analysis [22]. HPV detection was carried out by nested PCR using the MY09/11 consensus primer pairs [23] for the outer reaction ( $450 \mathrm{bp})$ and the MGP primer system [24] for the inner reaction ( $150 \mathrm{bp})$ [25]. The method has been evaluated $95 \%$ proficient for detection of HPV16, 18, 31, 33, 35, 39, 45, 52, $56,58,59,66$ and 68 b with a specificity above $97 \%$ using a proficiency panel of HPV plasmids in the context of the 4th WHO HPV LabNet Proficiency Study for Evaluating HPV DNA Typing Methods (2010), [26]. A negative control sample, made of a reaction mixture without template DNA, was included in every set of five clinical specimens for each PCR run.

The amplified DNA was subjected to electrophoresis on a $7 \%$ polyacrylamide gel followed by staining with ethidium bromide and image analysis by the Gel Doc gel imaging system (Bio-Rad Laboratories Inc., Hercules, 
CA). HPV genotypes were identified by direct automated DNA sequencing analysis of MGP amplified products using both the forward GP5+ and the reverse GP6+ oligoprimers [27] at Eurofins Genomics GmbH (Ebersberg, DE). HPV genotypes were identified by alignment of HPV sequences with those present in the GenBank database using the BLASTn software (http://www.ncbi.nlm.nih.gov/blast/html). The DNA samples showing multiple peaks on the pherograms, compatible with multiple infections, were re-amplified using for the inner reaction biotinylated GP5+/GP6+ primers and resulting amplimers subjected to the reverse line blot assay (Qiagen Manchester Ltd., UK) for the detection of 18 HPV genotypes as described previously [28].

\section{Statistical analyses}

The statistical analysis was performed using the Epi Info 6 Statistical Analysis System Software (Version 6.04b, 1997, Centers for Disease Control and Prevention, USA). Unpaired $t$ test was used for comparisons of continuous variables (i.e. age); Yates-corrected $\chi^{2}$ test and, where appropriate, two-sided Fisher's exact test were used for comparison of categorical data. Differences were considered to be statistically significant when $P$ values were less than 0.05 .

\section{Results}

The study included 337 women with a mean age of 37.6 $( \pm 10.9)$ years diagnosed with normal cytology $(n=96)$, low grade SIL $(n=226)$ and high grade SIL $(n=15)$. The histological analysis was available for 224 women and rendered 82 NILM, 129 CIN1 and 13 CIN2/3 diagnoses, respectively (Table 1). Overall HPV DNA sequences were detected in 230 out of 337 (68.3\%) samples (Table 1). The mean age of HPV-negative and HPV-positive women was $38.5( \pm 11.8)$ and $37.2( \pm 10.6)$ years, respectively.

Table 1 Cytological and histological diagnosis of cervical scrapes and biopsies stratified by HPV status

\begin{tabular}{cccc}
\hline & $\begin{array}{c}\text { Cases } \\
n(\%)\end{array}$ & $\begin{array}{c}\text { HPV positive } \\
n(\%)\end{array}$ & $\begin{array}{c}\text { HPV negative } \\
n(\%)\end{array}$ \\
\hline Cytology & 337 & $230(68.3)$ & $107(31.8)$ \\
NILM* $^{*}$ & $96(28.5)$ & $35(15.2)$ & $61(57.0)$ \\
LSIL $^{*}$ & $226(67.1)$ & $181(78.7)$ & $45(42.1)$ \\
HSIL $^{*}$ & $15(4.5)$ & $14(6.1)$ & $1(0.9)$ \\
Histology $^{a}$ & 224 & $161(71.9)$ & $63(28.1)$ \\
NILM $^{*}$ & $82(36.6)$ & $54(65.8)$ & $28(34.2)$ \\
CIN1 $^{*}$ & $129(57.6)$ & $95(73.6)$ & $34(26.4)$ \\
CIN2/CIN3* $^{*}$ & $13(5.8)$ & $12(92.3)$ & $1(7.7)$ \\
\hline
\end{tabular}

*NILM negative for intraepithelial lesions or malignancy, LSIL low grade SIL; HSIL high grade SIL; CIN1, 2 and 3 cervical intraepithelial neoplasia grade 1, 2 or 3 ${ }^{a}$ The HPV status of each histological biopsy has been determined on the corresponding cytological sample
Among analyzed samples, $41.3 \%$ were positive for Group 1 HPV genotypes, 0.9 and 16.9\% for Group 2A and Group 2B, respectively, and 2.7\% for Group 3 HPV genotypes. Unclassified viruses were found in $12.2 \%$ of samples and represented $17.8 \%$ of all infections (Table 2).

The most common genotypes were HPV16 (11.9\%), HPV31 (5.3\%), HPV18 (3.9\%), HPV33 (3.3\%), HPV52 (3\%), HPV56 (3\%) HPV58 (2.4\%) and HPV59 (2.1\%) belonging to Group1; HPV53 (6.5\%) and HPV66 (6.2\%) of the Group 2; HPV6 (2.4\%) of the Group 3 and unclassified HPV type 81 (2.1\%). The frequency of all other genotypes was below $2 \%$ of all HPV infections (Table 2 ).

The higher prevalence of HPVs (71.3\%) was observed among women in the age group $18-30, P=0.659$. Single HPV infections were found in 59.8 and $63.4 \%$ of the women aged 18-30 and $\geq 31$ years, respectively. Multiple infections were observed in 11.5 and $4.5 \%$ of women aged $18-30$ and $\geq 31$ years, respectively. HPV16 was the most common type found in the two age groups $(11.5$ and $11.9 \%$, respectively) followed by HPV66 (8.1 and 5.5\%), HPV31 (6.9 and 4.5\%), HPV 53 (5.8 and 8.4\%), HPV58 (5.8\% in 18-30 age group), HPV18 (4.6 and 4\%) and HPV56 (4.6 and 2.5\%).

According to cervical cytology, the prevalence of HPV infection was $36.5,80$ and $93.3 \%$ in patients with NILM, low grade SIL and high grade SIL respectively (Table 2). Group $1 \mathrm{HPV}$ genotypes were detected in $21.9,46.5$, and $86.7 \%$ of NILM, low grade SIL and high grade SIL, respectively. Group 2B HPV genotypes were identified in 4.2, 21.7 and $26.7 \%$ of NILM, low grade SIL and high grade SIL. Group $3 \mathrm{HPV}$ types were detected in 2.1 and $3.1 \%$ of NILM and low grade SIL but in none high grade SIL. Moreover, unclassified HPV types were found in 8.3 and $14.6 \%$ of NILM and low grade SIL, respectively, but not in high grade SIL (Table 2). Figure 1 shows the relative frequency of Group 1, 2A and $2 \mathrm{~B}$ as well as of unclassified HPV genotypes among all HPV-positive NILM, low grade SIL and high grade SIL.

Multiple infections containing at least one HPV genotype of Group 1 were found in $4.5 \%$ of cases, while those containing no high risk HPV genotypes represented $1.5 \%$ of all analyzed samples. Multiple infections were observed in $2.1 \%$ of NILM, $6.6 \%$ of low grade SIL and $20 \%$ of high grade SIL.

HPV types targeted by the nonavalent HPV vaccine (HPV6, 11, 16, 18, 31, 33, 45, 52 and 58) were detected, alone or in association with other genotypes in $17.7 \%$ (17/96), 40.3\% (91/226) and 53.3\% (8/15) of NILM, low grade SIL and high grade SIL, respectively.

\section{Discussion}

This study provides a comprehensive information on the HPV prevalence and genotype distribution among a cohort of Italian women which were referred to a single 
Table 2 Frequency of group 1, 2A, 2B, 3 and unclassified HPV genotypes among NILM, low grade SIL and high grade SIL

\begin{tabular}{|c|c|c|c|c|c|}
\hline Species & HPV genotype ${ }^{a}$ & $\begin{array}{l}\text { All samples } \\
n=337(\%)\end{array}$ & $\begin{array}{c}\text { NILM } \\
n=96(\%)\end{array}$ & $\begin{array}{c}\text { LSIL } \\
n=226(\%)\end{array}$ & $\begin{array}{c}\text { HSIL } \\
n=15(\%)\end{array}$ \\
\hline & HPV Negative & $107(31.8)$ & $61(63.5)$ & $45(20.0)$ & $1(6.7)$ \\
\hline & HPV Positive & $230(68.3)$ & 35 (36.5) & $181(80.0)$ & $14(93.3)$ \\
\hline & Group 1 & & & & \\
\hline A9 & HPV16 & $40(11.9)$ & $5(5.2)$ & $30(13.3)$ & $5(33.3)$ \\
\hline A7 & HPV18 & $13(3.9)$ & $2(2.1)$ & $10(4.4)$ & $1(6.7)$ \\
\hline A9 & HPV31 & $18(5.3)$ & 0 & $17(7.5)$ & $1(6.7)$ \\
\hline A9 & HPV33 & $11(3.3)$ & $1(1.0)$ & $9(3.9)$ & $1(6.7)$ \\
\hline A9 & HPV35 & $2(0.6)$ & 0 & $1(0.4)$ & $1(6.7)$ \\
\hline A7 & HPV39 & $7(2.1)$ & $1(1.0)$ & $5(2.2)$ & $1(6.7)$ \\
\hline A7 & HPV45 & $7(2.1)$ & 0 & $7(3.1)$ & 0 \\
\hline A5 & HPV51 & $6(1.8)$ & 0 & $5(2.2)$ & $1(6.7)$ \\
\hline A9 & HPV52 & $10(3.0)$ & $4(4.2)$ & $6(2.7)$ & 0 \\
\hline A6 & HPV56 & $10(3.0)$ & $3(3.1)$ & $5(2.2)$ & $2(13.3)$ \\
\hline A9 & HPV58 & $8(2.4)$ & $3(3.1)$ & $5(2.2)$ & 0 \\
\hline \multirow[t]{3}{*}{ A7 } & HPV59 & $7(2.1)$ & $2(2.1)$ & $5(2.2)$ & 0 \\
\hline & Total Group 1 & $139(41.3)$ & $21(21.9)$ & $105(46.5)$ & $13(86.7)$ \\
\hline & Group 2A & & & & \\
\hline \multirow[t]{2}{*}{ A7 } & HPV68 & $3(0.9)$ & $1(1.0)$ & $2(0.8)$ & 0 \\
\hline & Group 2B & & & & \\
\hline A6 & HPV53 & $22(6.5)$ & $2(2.1)$ & $19(8.4)$ & $1(7.1)$ \\
\hline A6 & HPV66 & $21(6.2)$ & $1(1.0)$ & $17(7.5)$ & $3(21.4)$ \\
\hline A9 & HPV67 & $3(0.9)$ & 0 & $3(1.3)$ & 0 \\
\hline A7 & HPV70 & $5(1.5)$ & 0 & $5(2.2)$ & 0 \\
\hline A11 & HPV73 & $20.6)$ & 0 & $2(0.9)$ & 0 \\
\hline A5 & HPV82 & $2(0.6)$ & $1(1.0)$ & $1(0.4)$ & 0 \\
\hline A11 & HPV34 & $1(0.3)$ & 0 & $1(0.4)$ & 0 \\
\hline \multirow[t]{3}{*}{ A7 } & HPV85 & $1(0.3)$ & 0 & $1(0.4)$ & 0 \\
\hline & Total Group 2B & $57(16.9)$ & $4(4.2)$ & $49(21.7)$ & $4(26.7)$ \\
\hline & Group 3 & & & & \\
\hline $\mathrm{A} 10$ & HPV6 & $8(2.4)$ & $2(2.1)$ & $6(2.7)$ & 0 \\
\hline \multirow[t]{3}{*}{$\mathrm{A} 10$} & HPV11 & $1(0.3)$ & 0 & $1(0.4)$ & 0 \\
\hline & Total Group 3 & $9(2.7)$ & $2(2.1)$ & $7(3.1)$ & 0 \\
\hline & Unclassified & & & & \\
\hline A3 & HPV81 & $7(2.1)$ & $1(1.0)$ & $6(2.7)$ & 0 \\
\hline $\mathrm{A} 1$ & HPV42 & $5(1.5)$ & 0 & $5(2.2)$ & 0 \\
\hline A3 & HPV62 & $6(1.8)$ & $1(1.0)$ & $5(2.2)$ & 0 \\
\hline $\mathrm{A} 10$ & HPV55 & $4(1.2)$ & $1(1.0)$ & $3(1.3)$ & 0 \\
\hline A3 & HPV89 & $4(1.2)$ & $3(3.1)$ & $1(0.4)$ & 0 \\
\hline A8 & HPV91 & $4(1.2)$ & 0 & $4(1.8)$ & 0 \\
\hline A13 & HPV54 & $3(0.9)$ & 0 & $3(1.3)$ & 0 \\
\hline A14 & HPV90 & $3(0.9)$ & $1(1.0)$ & $2(0.9)$ & 0 \\
\hline A3 & HPV84 & $2(0.6)$ & $1(1.0)$ & $1(0.4)$ & 0 \\
\hline A3 & HPV61 & $1(0.3)$ & 0 & $1(0.4)$ & 0 \\
\hline
\end{tabular}


Table 2 Frequency of group 1, 2A, 2B, 3 and unclassified HPV genotypes among NILM, low grade SIL and high grade SIL (Continued)

\begin{tabular}{llcccc}
\hline Species & HPV genotype $^{a}$ & $\begin{array}{c}\text { All samples } \\
n=337(\%)\end{array}$ & $\begin{array}{c}\text { NILM } \\
n=96(\%)\end{array}$ & $\begin{array}{c}\text { LSIL } \\
n=226(\%)\end{array}$ & $1(0.4)$ \\
A3 & HPV83 & $1(0.3)$ & 0 & $1(0.4)$ & 0 \\
B1 & HPV12 & $1(0.3)$ & 0 & $33(14.6)$ & 0 \\
& Total Unclassified & $41(12.2)$ & $8(8.3)$ & 0 \\
\hline
\end{tabular}

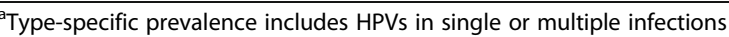

Centre for colposcopy following a diagnosis of abnormal cytology. As expected, the overall prevalence of high risk HPVs (Group 1), particularly HPV16, was significantly higher among high grade SIL (86.7\%) compared to low grade SIL (46.5\%) and NILM (17.7\%), $P<0.001$. Moreover, the probably and possibly carcinogenic HPVs (Group 2A and 2B) were found in 5.2, 22.6 and $26.7 \%$ of NILM, low grade SIL and high grade SIL, respectively.

As expected, the infection rates of both high and low risk viruses observed in our study are comparable to that obtained in other studies including Italian women participating in opportunistic screenings but higher than those observed among Italian women attending organized cervical cancer screening programs [17, 19].

Interestingly, we have identified 12 unclassified genotypes in $8.3 \%$ of NILM and in $14.6 \%$ of low grade SIL but in none of high grade SIL. The inverse correlation between infection frequency and disease severity suggests a limited role for such viruses in cervical carcinogenesis in the analyzed population. Among the unclassified HPVs the genotypes 81, 42, 62 and 91 were the most frequent being found in 2.7, 2.2, 2.2 and 1.8\% of low grade SIL, respectively, while the genotype 89 was the most frequent (3.1\%) among NILM cases. Despite the low rate of unclassified HPV genotypes in high grade SIL among the women included in the present study, it is important to report that unclassified HPV 54, 61, 62 and 81 represented $27.8 \%$ of all infections among HIV-positive Italian women diagnosed with high grade SIL, suggesting that compromised immune system could be not able to limit the "weak oncogenic" activity of some unclassified viruses [29]. Accordingly, Garbuglia et al. found that HPV62 and HPV81 were associated, as single infections, with 9.1 and $4.5 \%$ of high grade SIL, respectively, among HIV-positive women [30]. However, the frequency of unclassified HPV genotypes and their oncogenic risk remains underestimated because they are not included in the HPV assays commonly used to detect and characterize HPV genotypes in the majority of studies performed among HIV-negative and HIV-positive women [31, 32].

Cell transformation by HPVs mainly relies on the ability of the viral E6 protein to bind and degrade the p53 oncosuppressor. Mesplède et al. (2012) by performing a quantitative measurement of p53 degradation by the E6 of 29 different HPV genotypes showed that all Group 1
HPVs and several Groups 2A and 2B genotypes (HPV26, $30,34,53,66,68,69,70,73,82,97)$ were able to suppress p53 by binding and degradation [12]. Studies evaluating the ability of E6 proteins encoded by unclassified HPVs to bind p53 are warranted in order to understand the oncogenic potential of such viruses.

According to our results, the dynamic of unclassified HPVs seems to be stable over the years. In fact, a previous study performed in 2006 in our Centre showed that HPV62 and 81 were the most common unclassified genotypes among SIL samples [16, 20].

In the present study, multiple infections were more frequent in low grade (6.6\%) and high grade SIL (20\%) than in NILM (2.1\%). The majority of such infections (75\%) contained at least one HPV genotype of Group 1, while in the remaining $25 \%$ various combinations of low risk and unknown risk HPV genotypes were detected. Previous studies showed that multiple HPV infections are not associated to the severity of cervical lesions since they were as common in ICC or HSIL as in LSIL or NILM [33]. However, the coinfections of HPV16 and HPV68 caused a significant increase in the risk of high grade SIL and invasive cervical cancer $(\mathrm{OR}=16.5, P=$ $0.0002)$ compared to that found for HPV16 $(\mathrm{OR}=1.9$, $P=0.003)$ or HPV68 (OR $=3.5, P=0.38)$ as single infections, suggesting a synergistic effect between the two viruses [33].

Vaccination against high risk HPVs represents a primary prevention measure for anogenital cancers and squamous intraepithelial lesions caused by those HPV types. The recently licensed nonavalent HPV vaccine targets the seven high-risk HPV genotypes most frequently detected in invasive cervical cancer worldwide (HPV16, 18, 31, 33, 45, 52 and 58) and the low risk HPV genotypes 6 and 11 causing benign genital papillomas [3436]. Considering the frequency of these nine HPVs among the analyzed women, the use of nonavalent vaccine would be able to prevent more than $50 \%$ of HPV infections. In particular, vaccination would prevent 40.3 and $53.3 \%$ of low grade SIL and high grade SIL, respectively.

An important limitation of this study was that the self-referred women to the gynecologic center were likely not representative of the general population. Indeed, the HPV prevalence in this cohort was much 


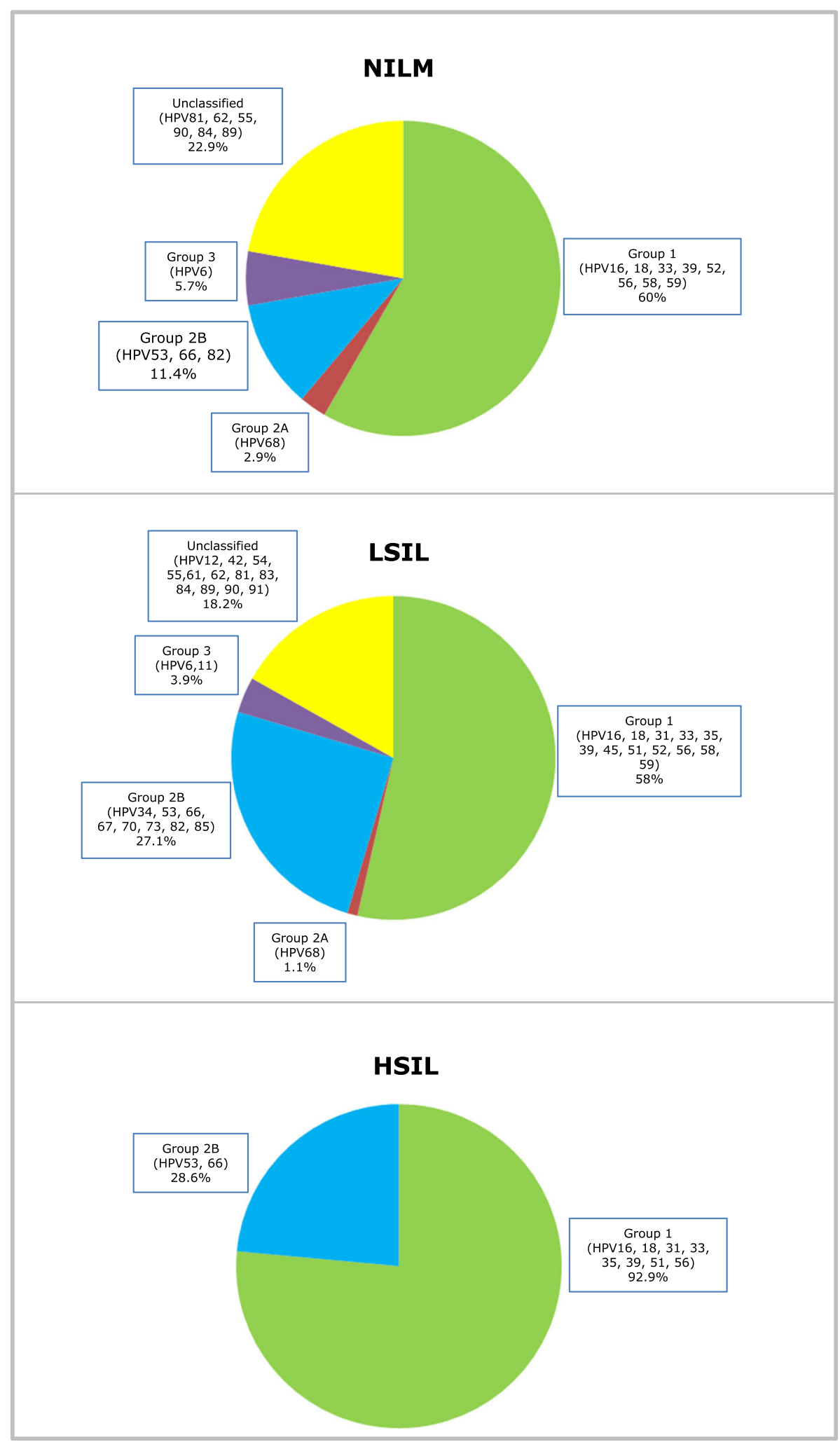

Fig. 1 Distribution of Group 1, 2A, 2B, 3 and unclassified HPVs in NILM, low grade SIL (LSIL) and high grade SIL (HSIL). Representativeness of the genotypes contained in each Group is expressed as percentage of all HPV positive cases in each category 
higher than in the Italian cervical cancer screening population. Moreover, the behavioral risk factors, such as the number of sexual partners and condom use, have not been considered, and the follow up of infected women has not been performed precluding the possibility to evaluate the persistence over the time of unclassified viruses. However, the use of broad spectrum consensus primers able to amplify all 62 mucosotropic HPV genotypes allowed to determine the global distribution of risk classified and unclassified HPVs in the study population.

The application of high-throughput sequencing technology and metagenomic analyses have recently enabled the discovery of many novel HPVs and that the HPV heterogeneity in healthy humans is very complex [37, 38]. It remains to be investigated whether the unclassified virus coinfections have a protecting role, by interfering with the activity of oncogenic viruses or by stimulating the immune cross-reaction, or have a synergistic effect with high risk HPVs facilitating cervical neoplasia development [38].

\section{Conclusions}

Our results show that the majority of low and high grade SIL in women referred for colposcopy at gynecological outpatient clinic of our Center are caused by Group 1 HPVs. The relative high prevalence of unclassified HPVs in low grade SIL and NILM and their absence in high grade SIL suggests that these viruses have a marginal role in cervical neoplasia in the general population. However, the identification of unclassified HPVs in HIV positive women with high grade lesions observed in previous studies, suggests that uncommon and unclassified HPV genotypes need to be characterized in immune compromised patients to allow a correct clinical management.

\section{Abbreviations \\ HPV: Human papillomavirus; NILM: Negative for intraepithelial lesion or malignancy; PCR: Polymerase chain reaction; SIL: squamous intraepithelial lesion}

\section{Acknowledgements}

We are grateful to Immacolata Di Biase, Noemy Starita, Marianna Tortora for technical support.

\section{Funding}

This project and the publication cost was supported by the research grant. Ricerca Corrente N. 2611892 from the Ministero della Salute.

\section{Availability of data and materials}

Authors can confirm that all relevant data are included in the article and materials are available on request from the authors.

\section{Authors' contributions}

CA performed the experimental analysis and drafted the manuscript; GS and SG enrolled the patients and collected clinical samples; MPC, VS, SL and GB performed pathological evaluation; LB performed the statistical analysis; FMB obtained the grant and supervised the project; MLT designed the research project and wrote he manuscript. All authors reviewed the manuscript. All authors read and approved the final manuscript.

\section{Ethics approval and consent to participate}

This study was approved by the Institutional Scientific Board and is in accordance with the principles of the Declaration of Helsinki.

Consent for publication

Not applicable.

\section{Competing interests}

The authors declare that they have no competing interests.

\section{Publisher's Note}

Springer Nature remains neutral with regard to jurisdictional claims in published maps and institutional affiliations.

\section{Author details \\ ${ }^{1}$ Molecular Biology and Viral Oncology Unit, Istituto Nazionale Tumori IRCCS "Fondazione G. Pascale", via M Semmola, 80131 Naples, Italy. ${ }^{2}$ Gynecology Oncology Unit, Istituto Nazionale Tumori IRCCS "Fondazione G. Pascale", 80131 Naples, Italy. ${ }^{3}$ Department of Pathology, Istituto Nazionale Tumori IRCCS "Fondazione G. Pascale", 80131 Naples, Italy.}

Received: 17 April 2018 Accepted: 13 July 2018

Published online: 24 July 2018

\section{References}

1. Bravo IG, Felez-Sanchez M. Papillomaviruses: viral evolution, cancer and evolutionary medicine. Evol Med Public Health. 2015;2015:32-51.

2. Bzhalava D, Guan P, Franceschi S, Dillner J, Clifford G. A systematic review of the prevalence of mucosal and cutaneous human papillomavirus types. Virology. 2013;445:224-31.

3. Zur Hausen $\mathrm{H}$, de Villiers EM. Reprint of: cancer "causation" by infections-individual contributions and synergistic networks. Semin Oncol. 2015;42: 207-22.

4. de Villiers EM, Fauquet C, Broker TR, Bernard HU, Zur Hausen H. Classification of papillomaviruses. Virology. 2004;324:17-27.

5. Bernard HU, Burk RD, Chen Z, van DK, Zur Hausen H, de Villiers EM. Classification of papillomaviruses (PVs) based on $189 \mathrm{PV}$ types and proposal of taxonomic amendments. Virology. 2010;401:70-9.

6. Bzhalava D, Eklund C, Dillner J. International standardization and classification of human papillomavirus types. Virology. 2015;476:341-4.

7. Guan P, Howell-Jones R, Li N, Bruni L, de Sanjosé S, Franceschi S, Clifford GM. Human papillomavirus types in 115,789 HPV-positive women: a metaanalysis from cervical infection to cancer. Int J Cancer. 2012;131:2349-59.

8. Munoz N, Bosch FX, de Sanjose S, Herrero R, Castellsague X, Shah KV, Snijders PJ, Meijer CJ. Epidemiologic classification of human papillomavirus types associated with cervical cancer. N Engl J Med. 2003;348:518-27.

9. IARC: IARC monographs on the evaluation of carcinogenic risks to humans. A Review of Human Carcinogens Part B: Biological Agents. Lyon, France; 2011.

10. Biological agents. Volume 100 B. A review of human carcinogens. IARC Monogr Eval Carcinog Risks Hum 2012, 100:1-441.

11. Schiffman M, Clifford G, Buonaguro FM. Classification of weakly carcinogenic human papillomavirus types: addressing the limits of epidemiology at the borderline. Infect Agent Cancer. 2009;4:8.

12. Mesplede T, Gagnon D, Bergeron-Labrecque F, Azar I, Senechal H, Coutlee F, Archambault J. p53 degradation activity, expression, and subcellular localization of E6 proteins from 29 human papillomavirus genotypes. J Virol. 2012;86:94-107.

13. Bruni L, Diaz M, Castellsague X, Ferrer E, Bosch FX, de Sanjosé S. Cervical human papillomavirus prevalence in 5 continents: Meta-analysis of 1 million women with normal cytological findings. J Infect Dis. 2010;

14. Baussano I, Franceschi S, Gillio-Tos A, Carozzi F, Confortini M, Dalla Palma P, De Lillo M, Del Mistro A, De Marco L, Naldoni C, Pierotti P, Schincaglia P, Segnan N, Zorzi M, Giorgi-Rossi P, Ronco G. Difference in overall and agespecific prevalence of high-risk human papillomavirus infection in Italy: evidence from NTCC trial. BMC Infect Dis. 2013;13:238.

15. Carozzi FM, Tornesello ML, Burroni E, Loquercio G, Carillo G, Angeloni C, Scalisi A, Macis R, Chini F, Buonaguro FM, Giorgi-Rossi P. Prevalence of human papillomavirus types in high-grade cervical intraepithelial neoplasia and Cancer in Italy. Cancer Epidemiol Biomark Prev. 2010;19:2389-400. 
16. Tornesello ML, Duraturo ML, Botti G, Greggi S, Piccoli R, De Palo G, Montella M, Buonaguro L, Buonaguro FM. Prevalence of alpha-papillomavirus genotypes in cervical squamous intraepithelial lesions and invasive cervical carcinoma in the Italian population. J Med Virol. 2006;78:1663-72.

17. Giorgi Rossi P, Bisanzi S, Paganini I, Di lasi A, Angeloni C, Scalisi A, Macis R, Pini MT, Chini F, Carozzi FM. Prevalence of HPV high and low risk types in cervical samples from the Italian general population: a population based study. BMC Infect Dis. 2010;10:214.

18. Giorgi Rossi P, Sideri M, Carozzi FM, Vocaturo A, Buonaguro FM, Tornesello ML, Burroni E, Mariani L, Boveri S, Zaffina LM, Chini F. HPV type distribution in invasive cervical cancers in Italy: pooled analysis of three large studies. Infect Agent Cancer. 2012;7:26.

19. Galati L, Peronace C, Fiorillo MT, Masciari R, Giraldi C, Nistico S, Minchella P, Maiolo V, Barreca GS, Marascio N, Lamberti AG, Giancotti A, Lepore MG, Greco F, Mauro MV, Borelli A, Bocchiaro GL, Surace G, Liberto MC, Foca A. Six years genotype distribution of human papillomavirus in Calabria region, southern Italy: a retrospective study. Infect Agent Cancer. 2017:12:43.

20. Tornesello ML, Losito S, Benincasa G, Fulciniti F, Botti G, Greggi S, Buonaguro L, Buonaguro FM. Human papillomavirus (HPV) genotypes and HPV16 variants and risk of adenocarcinoma and squamous cell carcinoma of the cervix. Gynecol Oncol. 2011;121:32-42.

21. Del Prete R, Ronga L, Addati G, Magrone R, Di Carlo D, Miragliotta G. Prevalence, genotype distribution and temporal dynamics of human papillomavirus infection in a population in southern Italy. Infez Med. 2017; 25:247-57.

22. Tornesello ML, Cassese R, De Rosa N, Buonaguro L, Masucci A, Vallefuoco G, Palmieri S, Schiavone V, Piccoli R, Buonaguro FM. High prevalence of human papillomavirus infection in eastern European and west African women immigrants in South Italy. APMIS. 2011;119:701-9.

23. Resnick RM, Cornelissen MT, Wright DK, Eichinger GH, Fox HS, ter SJ, Manos MM. Detection and typing of human papillomavirus in archival cervical cancer specimens by DNA amplification with consensus primers. J Natl Cancer Inst. 1990;82:1477-84.

24. Soderlund-Strand A, Carlson J, Dillner J. Modified general primer PCR system for sensitive detection of multiple types of oncogenic human papillomavirus. J Clin Microbiol. 2009;47:541-6.

25. Tornesello ML, Loquercio G, Tagliamonte M, Rossano F, Buonaguro L, Buonaguro FM. Human papillomavirus infection in urine samples from male renal transplant patients. J Med Virol. 2010;82:1179-85.

26. Eklund C, Zhou T, Dillner J. Global proficiency study of human papillomavirus genotyping. J Clin Microbiol. 2010;48:4147-55.

27. de Roda Husman AM, Walboomers JM, Meijer CJ, Risse EK, Schipper ME, Helmerhorst TM, Bleker OP, Delius H, van den Brule AJ, Snijders PJ. Analysis of cytomorphologically abnormal cervical scrapes for the presence of 27 mucosotropic human papillomavirus genotypes, using polymerase chain reaction. Int J Cancer. 1994;56:802-6.

28. Giorgi Rossi P, Chini F, Bisanzi S, Burroni E, Carillo G, Lattanzi A, Angeloni C, Scalisi A, Macis R, Pini MT, Capparucci P, Guasticchi G, Carozzi FM, Prevalence Italian Working Group HPV. Distribution of high and low risk HPV types by cytological status: a population based study from Italy. Infect Agent Cancer. 2011;6:2.

29. Tornesello ML, Duraturo ML, Giorgi-Rossi P, Sansone M, Piccoli R, Buonaguro L, Buonaguro FM. Human papillomavirus (HPV) genotypes and HPV16 variants in human immunodeficiency virus-positive Italian women. J Gen Virol. 2008;89:1380-9.

30. Garbuglia AR, Piselli P, Lapa D, Sias C, Del Nonno F, Baiocchini A, Cimaglia C, Agresta A, Capobianchi MR. Frequency and multiplicity of human papillomavirus infection in HIV-1 positive women in Italy. J Clin Virol. 2012; 54:141-6.

31. Clifford GM, Goncalves MA, Franceschi S. Human papillomavirus types among women infected with HIV: a meta-analysis. AIDS. 2006;20:2337-44.

32. Clifford GM, Tully S, Franceschi S. Carcinogenicity of human papillomavirus (HPV) types in HIV-positive women: a Meta-analysis from HPV infection to cervical Cancer. Clin Infect Dis. 2017;64:1228-35.

33. Carrillo-García A, Ponce-de-León-Rosales S, Cantú-de-León D, FragosoOntiveros V, Martínez-Ramírez I, Orozco-Colín A, Mohar A, Lizano M. Impact of human papillomavirus coinfections on the risk of high-grade squamous intraepithelial lesion and cervical cancer. Gynecol Oncol. 2014;134:534-9.

34. HPV vaccine works against nine viral types. Cancer Discov 2014, 4:OF2-8290.

35. de Sanjose S, Quint WG, Alemany L, Geraets DT, Klaustermeier JE, Lloveras B, Tous S, Felix A, Bravo LE, Shin HR, Vallejos CS, De Ruiz PA, Lima MA,
Guimera N, Clavero O, Alejo M, Llombart-Bosch A, Cheng-Yang C, Tatti SA, Kasamatsu E, lljazovic E, Odida M, Prado R, Seoud M, Grce M, Usubutun A, Jain A, Suarez GA, Lombardi LE, Banjo A, Menendez C, Domingo EJ, Velasco J, Nessa A, Chichareon SC, Qiao YL, Lerma E, Garland SM, Sasagawa T,

Ferrera A, Hammouda D, Mariani L, Pelayo A, Steiner I, Oliva E, Meijer CJ, AlJassar WF, Cruz E, Wright TC, Puras A, Llave CL, Tzardi M, Agorastos T, Garcia-Barriola V, Clavel C, Ordi J, Andujar M, Castellsague X, Sanchez Gl, Nowakowski AM, Bornstein J, Munoz N, Bosch FX. Human papillomavirus genotype attribution in invasive cervical cancer: a retrospective crosssectional worldwide study. Lancet Oncol. 2010;11:1048-56.

36. Li N, Franceschi S, Howell-Jones R, Snijders PJ, Clifford GM. Human papillomavirus type distribution in 30,848 invasive cervical cancers worldwide: variation by geographical region, histological type and year of publication. Int J Cancer. 2011;128:927-35.

37. Liu Z, Yang S, Wang Y, Shen $Q$, Yang Y, Deng X, Zhang W, Delwart E. Identification of a novel human papillomavirus by metagenomic analysis of vaginal swab samples from pregnant women. Virol J. 2016;13:122.

38. Ma Y, Madupu R, Karaoz U, Nossa CW, Yang L, Yooseph S, Yachimski PS, Brodie EL, Nelson KE, Pei Z. Human papillomavirus community in healthy persons, defined by metagenomics analysis of human microbiome project shotgun sequencing data sets. J Virol. 2014;88:4786-97.

Ready to submit your research? Choose BMC and benefit from:

- fast, convenient online submission

- thorough peer review by experienced researchers in your field

- rapid publication on acceptance

- support for research data, including large and complex data types

- gold Open Access which fosters wider collaboration and increased citations

- maximum visibility for your research: over $100 \mathrm{M}$ website views per year

At $\mathrm{BMC}$, research is always in progress.

Learn more biomedcentral.com/submissions 